\title{
Effect of ionic surfactants on the viscoelastic properties of chiral nematic cellulose nanocrystal suspensions
}

Damoon Ranjbar and Savvas G. Hatzikiriakos

Department of Chemical and Biological Engineering, The University of British Columbia, Vancouver, British Columbia V6T 1Z3, Canada

\section{Supporting information}

Two Figures and Two additional Pages (three including this page) 

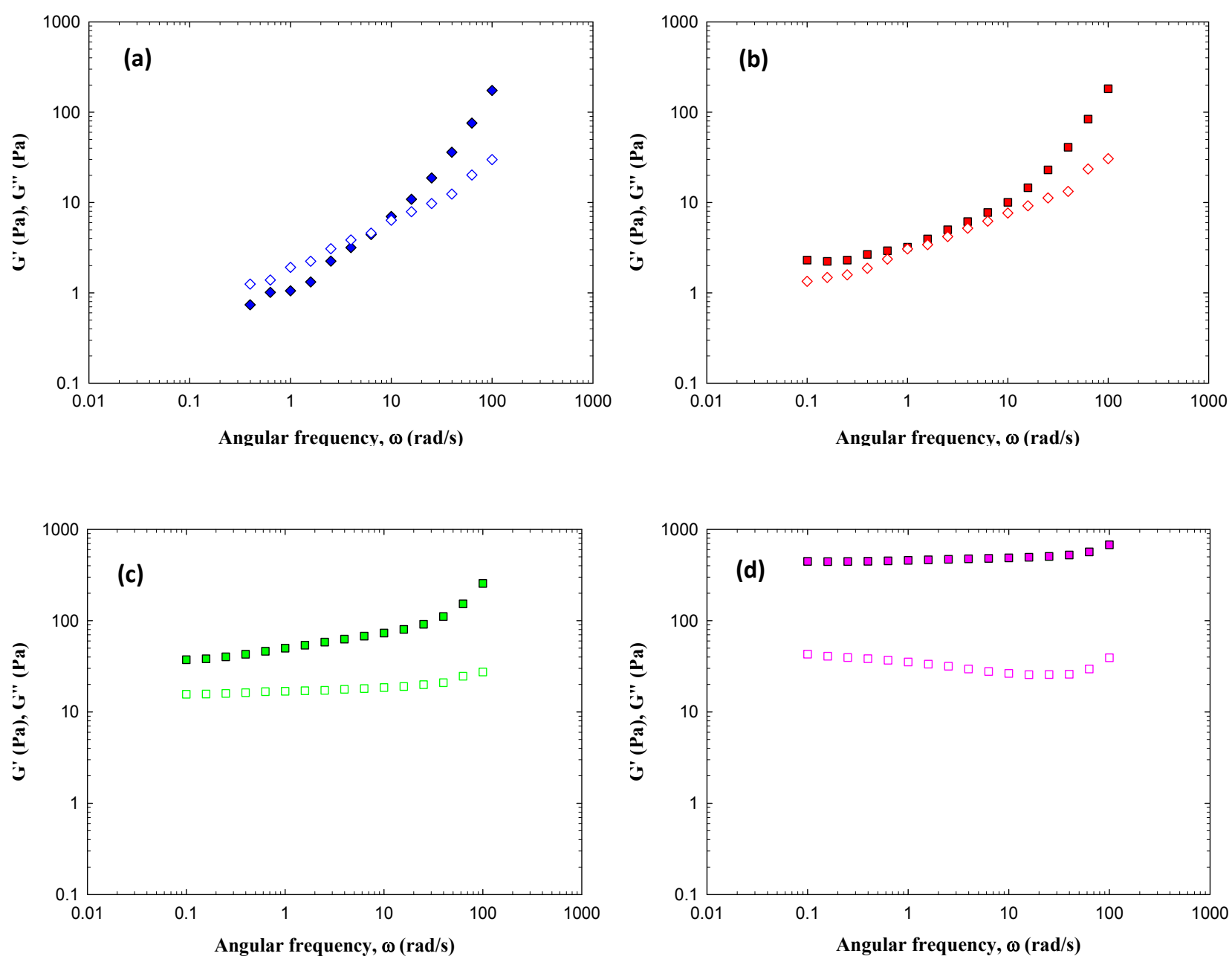

Figure S1. Storage modulus G' (solid symbols), and Loss modulus G" (open symbols) versus angular frequency (w) for $3 \mathrm{wt} \% \mathrm{CNC}$ suspensions in the presence of CTAB (a) $0.2 \mathrm{mM}$, (b) $0.4 \mathrm{mM}$, (c) $0.8 \mathrm{mM}$, and (d) $2 \mathrm{mM} \mathrm{CTAB}$ 

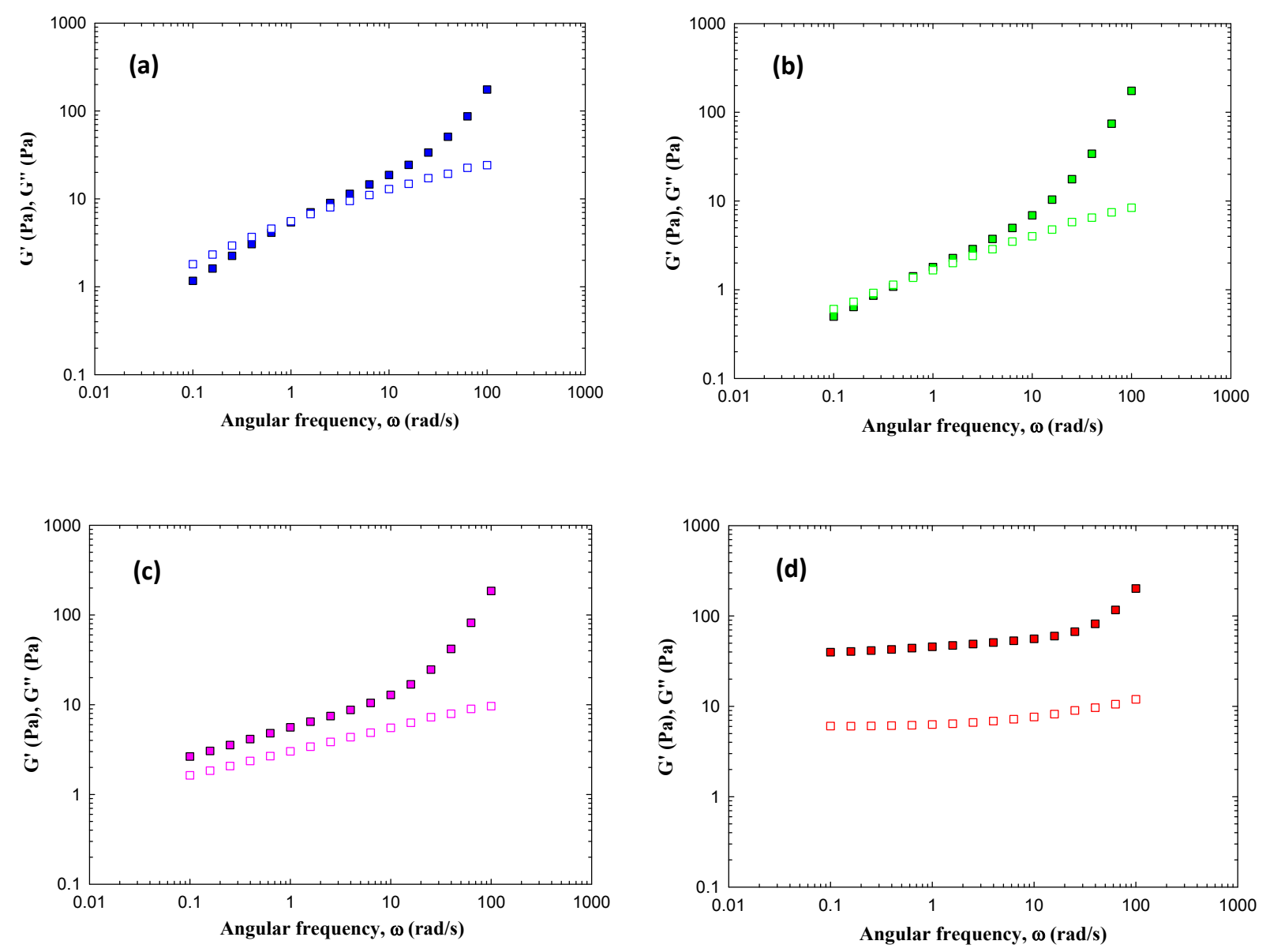

Figure S2. Storage modulus G' (solid symbols), and Loss modulus G" (open symbols) versus angular frequency $(\omega)$ for $3 \mathrm{wt} \% \mathrm{CNC}$ suspensions in the presence of SDS (a) $0.25 \mathrm{mM}$, (b) $3 \mathrm{mM}$, (c) $4 \mathrm{mM}$, and (d) $8 \mathrm{mM}$ SDS 